\title{
An exploratory study of the effect of labor pain management on postpartum depression among Chinese women
}

\author{
Yao Zhang ${ }^{1,2}$, Linda Johnston ${ }^{3}$, Dongmei Ma ${ }^{4}$, Fang Wang ${ }^{4}$, Xiaolong Zheng ${ }^{4}$, Xinfen $\mathrm{Xu}^{4,5}$ \\ ${ }^{1}$ Department of Nursing, School of Medicine, Zhejiang University, Hangzhou, China \\ ${ }^{2}$ Department of Midwifery, School of Nursing, Zhejiang Chinese Medical University, Hangzhou, China \\ ${ }^{3}$ Lawrence S. Bloomberg Faculty of Nursing, University of Toronto, Toronto, Canada \\ ${ }^{4}$ Department of Nursing, Women's Hospital, School of Medicine, Zhejiang University, Hangzhou, China \\ ${ }^{5}$ Department of Nursing, Haining Maternal and Child Health Care Hospital, Haining, China
}

\begin{abstract}
Objectives: The purpose of this study was to investigate the effects of pain relief during labor on the occurrence of potential postpartum depression in early postpartum among Chinese women.

Material and methods: A quasi-experimental study used, with a convenience sample of 565 women who delivered at the Women's Hospital, School of Medicine. Three types of pain relief were administered based on the women's preference (doula, $\mathrm{n}=301$; transcutaneous electrical nerve stimulation, $\mathrm{n}=51$; epidural analgesia, $\mathrm{n}=213$ ). Pain scores of participants were assessed using a 10-point visual analog scale during labor. The Edinburgh Postnatal Depression Scale was administered in person and by phone at three days and two to four weeks after delivery, respectively. All data were analyzed using SPSS 20.0. Results: Visual analog scale pain scores in the epidural analgesia group decreased significantly during labor compared to those of the other two groups. The occurrence of potential postpartum depression at three days was $6.6 \%$ in the epidural analgesia group, $1.3 \%$ in the doula group, and $2 \%$ in the transcutaneous electrical nerve stimulation group $(P=0.04)$. Furthermore, potential postpartum depression occurred at two to four weeks after childbirth in $16 \%(34 / 213)$ of the participants in the epidural analgesia group, 7.3\% (22/301) of those who received doula support, and in 7.8\% (4/51) of those in the transcutaneous electrical nerve stimulation group $(P=0.006)$.

Conclusions: The results indicated that epidural analgesia was an effective pain relief method during labor. However, it did not reduce the occurrence of potential postpartum depression and was associated with higher postnatal depression scores.

Key words: labour pain management; labour analgesia; postpartum depression; edinburgh postpartum depression scale

Ginekologia Polska 2018; 89, 11:627-636
\end{abstract}

\section{INTRODUCTION}

Postpartum depression (PPD) is defined as a mental and behavioral disorder associated with the puerperium commencing within four weeks of delivery [1]. This disorder (including postnatal blues) develops in $50 \%$ to $70 \%$ of all women following childbirth, and it can present any time from early after delivery throughout the baby's first year of life, but mostly beginning at three or four days postpartum and usually developing within the first two to twelve weeks [2]. Manifestations include insomnia, depressive symptoms, fatigue, anxiety, poor concentration, postpartum anxiety, irritability, and severe depression. Further, PPD may have dramatic and long-lasting effects not only on the woman but also on her child and family [3].

According to the Centers for Disease Control and Prevention in the United States, 11 to $20 \%$ of women who give birth will have PPD symptoms [4]. A systematic review of 67 studies conducted in 17 Asian countries among 32,307 women [5] found a prevalence of PPD ranging from $3.5 \%$ to $63.3 \%$, where Malaysia (3.9\%) and Pakistan (63.3\%) had the lowest and highest rates of PPD, respectively. The authors suggest the large range in prevalence may be because of different 
screening/diagnostic tools, different cut-off points on the Edinburgh Postpartum Depression Scale (EPDS) for identifying PPD cases, and various time points when PPD symptoms are measured.

In China, the prevalence of PPD has ranged between $6.5 \%$ and $29.5 \%$ over the past five years; it is estimated that 3.74 million women in China are identified as experiencing PPD every year [6]. A Chinese study by Wan et al. [7] revealed that the incidence of PPD was different in different regions of the country, with the lowest incidence being $10.9 \%$, and the highest $16.4 \%$. The authors indicated that underdeveloped areas had higher rates of PPD, with a higher prevalence in the western part of China compared to the more economically developed eastern part of the country.

The mechanism underpinning PPD is unclear, and early screening for PPD is difficult because the definition of PPD remains controversial. In addition, researchers report that the time period for the onset of PPD varies from two weeks to 18 months [8]. In comparing the diagnosis, timing, and symptom patterns of PPD and major depressive disorder (MDD), there are distinct differences that may partially explain why PPD is underdiagnosed and undertreated. However, there are various risk factors influencing a mother's psychological status after childbirth. According to a meta-analysis by O'Hara et al. [9], the major risk factors before delivery included mood instability during pregnancy, lack of social support during pregnancy, and the mother's concerns about the safety of delivery. The main risk factors post-delivery were low economic status of the family, lack of support from husband and family, and a bad relationship with the spouse. Undeniably, previous depression and antenatal depression were also included as the two greatest risks for PPD.

Although pain during labor is the most intense pain that many women will suffer during their lives, perinatal pain was not reported as a risk factor for PPD in the study by O'Hara et al. [9].

However, the relationship between severity of labor pain and PPD has been investigated in a few studies. Hiltunen et al. [10], in their prospective follow-up study $(\mathrm{N}=162)$, first reported that epidural analgesia is an effective approach for pain relief that also decreased EPDS scores in the first postnatal week. The lack of reported measurements of pain scores during analgesia makes the results of the study difficult to interpret. A more recent prospective cohort study by Ding et al. [11] indicated that patients $(\mathrm{N}=214)$ who received epidural analgesia during labor had a lower risk of PPD at three days and six weeks after delivery compared with the control group. A single, institutional, retrospective, observational cohort study by Lim et al. [12] also found that women with higher improvements in pain were associated with lower EPDS scores at six weeks postpartum. Eisenach et al.'s [13] prospective, longitudinal cohort study ( $\mathrm{N}=1228$ ) reported that the severity of acute pain during labor and persistent pain after delivery, but not mode of delivery (e.g., cesarean delivery or vaginal delivery), had negative effects on daily living-a significant and independent risk factor for PPD—-measured at eight weeks postpartum.

Gaudet et al.'s [14] retrospective study with a sample of Canadian postpartum women $(\mathrm{N}=5614)$ indicated that chronic perinatal pain (e.g., vaginal, cesarean incision site, breasts, back, and severe headaches) was strongly associated with PPD symptoms and was a major risk factor for PPD. These relatively few studies are consistent in concluding that there is a relationship between pain in the perinatal period and the development of PPD. Moreover, a prospective study ( $N=1649$ ) by Jung et al. [15] indicated that women with severe fear of childbirth experienced significantly more labor pain than women without severe fear of childbirth $(P<0.01)$. We hypothesize that anxiety and fear of labor pain, which underpins a woman's choice of analgesia, may be a risk factor for PPD, rather than the analgesia itself.

The purpose of the current study was to investigate whether the effects of pain relief during labor influence the occurrence of potential PPD in early postpartum in a population of Chinese mothers.

\section{MATERIALS AND METHODS Design and Setting}

A quasi-experimental study design was used. The study was undertaken in the Women's Hospital, School of Medicine, a public maternity hospital with 1120 beds, and 20,000 deliveries per year that provides a 24-hour doula service and 24-hour epidural analgesia service in Zhejiang province in China.

\section{Participants}

A convenience sample of pregnant women who delivered in the hospital was recruited between September 2012 and October 2013. The participants who met the following eligibility criteria were asked to participate: a maternal age of 20-35 years, being literate, had completed full-term pregnancy (between 37 to 42 weeks), a low-risk pregnancy, no history of smoking and alcohol abuse, and no history of depression.

Exclusion criteria included the mother having a cervical dilation of $3 \mathrm{~cm}$ or more even before the start of labor, having a history of psychiatric disease, any need for emergency intervention, emergency cesarean for any reason during labor, and having serious complications of childbirth.

The participants were offered interventions when the cervix was dilated to $3 \mathrm{~cm}$ in the active phase of labor. The intervention was one of three types of pain relief during labor: doula support, transcutaneous electrical nerve stimulation, 
and epidural analgesia. Allocation to the intervention group was based on the women's preference, and participants could not be blinded because the women were informed of the types of pain relief available during labor and made their decision based on their preference (whenever they wanted to change their analgesic method, they could withdraw from the study at any time). All eligible participants were informed about the study, and all of them provided written informed consent prior to participation. Further, they were informed that participation was completely voluntary and that withdrawal from the study was possible at any time without any negative repercussions.

The study protocol was approved by the Ethics Committee of the Women's Hospital, School of Medicine, Zhejiang University. All applicable procedures and policies regarding the ethical treatment of volunteer participants were followed. All data were registered on the Chinese Ethics Committee Clinical Trials Registry (ChiCTR-IPQ-15006310). Retrospectively registered on 27 April 2015.

\section{Data Collection}

When the participants were enrolled in the study, their pain during labor was assessed by an investigator not blinded to the intervention (XL. Zheng) by Visual Analogue Scale (VAS) scoring [16] at four different time points: (A) before labor analgesia; (B) following 30 mins of labor analgesia; (C) following labor analgesia for 60 mins; and (D) following labor analgesia for 120 mins. All participants were also asked to complete the paper-based Chinese version of the EPDS [11] in hospital (three days after childbirth) and after two to four weeks at home by phone as part of the follow-up study. Data were collected in hard copy and then transferred to SPSS 20. The investigator who analyzed the data was blinded to the intervention that was received.

Demographic data regarding maternal age, level of education attainment, and employment were collected verbally using a self-designed questionnaire. Intrapartum data including the duration of labor, mode of delivery, and VAS pain scores (10-point scale: 0 indicated no pain and 10 indicated the worst pain) during analgesia were documented. After delivery, neonatal information (including gestational age, gender, birth weight, and Apgar scores at 1 and 5 minutes after delivery) was recorded.

\section{Transcutaneous Electrical Nerve Stimulation (TENS)}

A form of non-pharmacological labor analgesia, TENS has been used for over 30 years in European countries [17]. There have been a number of systematic reviews/meta-analyses that have examined the efficacy of TENS for pain reduction in women with labor pain in the last seven years [18]. Additionally, TENS has been used by pregnant women for
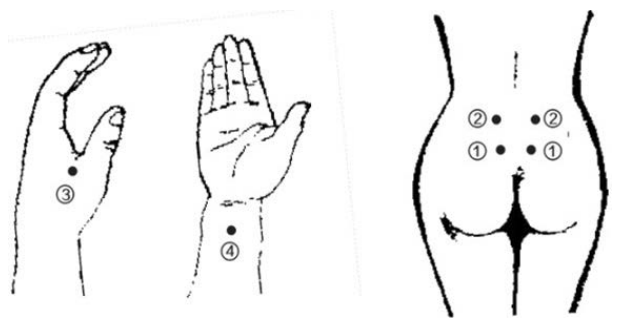

Figure 1. Placement of Transcutaneous Electrical Nerve Stimulation

many years without any reported side effects for either the mother or baby. In fact, it has been suggested that TENS enhances placental blood flow, although TENS has been used in the management of labor pain in China only since 2001 [19]. In our study, a portable TENS unit (GT-4A) was used that was the same type was as that in the study. There were two cables: $A$ and $B$, with two pairs of electrodes each (Fig. 1). The electrodes of cable $A$ were placed on the back of the hands (3) point) and wrists (4) point). The electrodes of cable $B$ were placed $1 \mathrm{~cm}$ laterally on either side of the spine at the T10 and S2 to S4 levels (1) and (2) points).

The TENS unit produces a modified biphasic asymmetric pulse, and it was set to an intermittent pulse width of $100 \mu \mathrm{s}$ and a frequency of $100 \mathrm{~Hz}$. The intensity was tailored according to the sensitivity of the participant, and TENS was administered between the time points at which the cervix was dilated to $3 \mathrm{~cm}$ and $10 \mathrm{~cm}$.

\section{Epidural Labor Analgesia}

Epidural labor analgesia was administered by an anesthetist. Epidural space puncture and catheterization were performed at the L2-L3 interspace when the cervix was dilated to $3 \mathrm{~cm}$. An initial loading dose of $10 \mathrm{~mL}$ of $0.1 \%$ ropivacaine plus $0.5 \mu \mathrm{g} / \mathrm{mL}$ sufentanil was administered. Analgesia was maintained with a mixture of $0.08 \%$ ropivacaine plus $0.4 \mu \mathrm{g} / \mathrm{mL}$ sufentanil, and the device was programmed to deliver a $6 \mathrm{~mL}$ bolus with a 15-minute lockout interval and a maximum dose of $24 \mathrm{~mL}$ per hour. Epidural labor analgesia was discontinued when the cervix was dilated to $10 \mathrm{~cm}$. If the women could not tolerate labor pain and were assessed by the midwife and anesthetist, they were given additional analgesia that would not influence labor. During epidural analgesia, the anesthetist and midwife had the responsibility for monitoring the fetal heart rate, uterine contractions, maternal blood pressure, and heart rate.

\section{Doula}

A doula (also called labor doula) is a trained professional who provides continuous physical, emotional, and informational support to a mother before, during, and shortly after childbirth to help her achieve the healthiest and most satisfying experience possible. Their provision of physical 
assistance and emotional support for women during labor has been shown to relieve labor pain [20]. Doulas, typically current or retired midwives, were introduced in China in the late 90's. Doulas in China are birth companions providing continuous support during labor until two hours postpartum. Over $70 \%$ of women are supported by a doula as normal practice in the delivery room in China but only once they reach at least a $3 \mathrm{~cm}$ cervical dilation. In this study, doula support was considered the "control group," and doulas were current or retired nurses with experience in midwifery and healthcare in the hospital. Doulas started to be in contact with women only when they reached a cervical dilation of $3 \mathrm{~cm}$ in the delivery room. They continuously accompanied the participants from the time the cervix was dilated to $3 \mathrm{~cm}$ until after childbirth.

\section{PPD Assessment}

The primary outcome was PPD at three days or two to four weeks. In the Diagnostic and Statistical Manual of Mental Disorders [21], PPD onset occurs within the first three to four weeks postpartum. However, clinicians and researchers alike have criticized this limited timeframe. In a recent study, it was reported that the time period of PPD ranged from two weeks to 18 months postpartum, with 12 months being the most common limit [22]. Additionally, it is recommended that the EPDS be used within two to three days postpartum or at the first after-delivery pediatric visit [23]. In our study, PPD was determined at three days and two to four weeks after delivery to screen potential early PPD, and, following consultation with psychological experts, we chose a cut-off score of 6 as the point indicating potential early PPD in the mainland Chinese population.

The reliability and validity of the Mainland Chinese version of the EPDS, which we used in our study, were satisfactory (over $90 \%$ ) in a sample of postnatal Chinese women and were consistent with those of the original study [24]. The EPDS is a 10-item self-reported questionnaire. Each item is rated from 0 to 3 , denoting increasing severity of symptoms, and with a possible maximum score of 30 . Although Lee et al. [25] recommended a cut-off score of 9 or 10 for screening depression at six weeks postpartum in a general Chinese postpartum population in Hong Kong, the EPDS is not a diagnostic tool but is to be used in conjunction with further evaluation. Such evaluation should continue within the 2-4-week postpartum visit for mothers determined to be at risk, as mood episodes can be lengthy and psychological sequelae increase with the duration of depressive symptoms. These sequelae take a heavy toll on women's functioning as well as the wellbeing of their children, as undetected PPD often develops into a more chronically depressive course. One study showed that two years later, $30.6 \%$ of women diagnosed with PPD at one month postpar- tum continued to score in the depressed range on the Beck Depression Inventory-II. Therefore, we consulted experts about using a cut-off score of 6 to screen the potential occurrence of early PPD.

\section{Pain Assessment}

The secondary outcome was pain scores measured by a VAS at different time points during the intervention period: before analgesia, 30 mins after analgesia, 60 mins after analgesia, and 120 mins after analgesia. Severity of pain was marked by the participants on a scale ranging from 1 to 10 , with 1 representing no pain and 10 representing the most painful situation experienced. The VAS pain score is considered to be one of the best methods available for the estimation of the intensity of pain in clinical studies, and it is easy to use [16].

To quantitatively assess the pain experienced by the participants, the classification system described in a study by colleagues [26] was used: ratings of 0 to 2 were considered minimal pain; 3 to 6 , mild pain; 7 to 8 , moderate pain; and 9 to 10 , severe pain.

\section{Statistical Analysis}

Continuous variables are presented as the mean \pm standard deviation (SD). Data for the three groups were compared with the use of an independent sample one-way ANOVA for more than two groups. Categorical variables are presented as the number of participants (percentage). Data were analyzed with the use of Chi-square for multinomial and Fisher's exact test (two-tails). Multivariable logistic regression analysis was conducted using a backward elimination method, wherein the initial model includes the maximum number of potential confounding variables and the model is reduced sequentially until only significant variables remain. Two-sided $P$ values $<0.05$ were regarded as significant. Statistical analyses were performed with the SPSS 20.0 software (SPSS Inc., Chicago, IL).

Sample size calculation was performed before as follows: As per the typically cited mean prevalence of PPD (0.15), according to the results of the power calculation, to obtain $80 \%$ power for the cases, the sample size should be at least 547.

\section{RESULTS \\ Participant Demographics}

Five hundred and seventy-nine women with term singleton pregnancies met the inclusion criteria during the study period. Fourteen women did not complete the study. Therefore, 565 participants were included in the final analyses. The details of the recruitment are shown in Figure 2.

There were no significant differences in maternal variables among the three groups (Tab. 1). Overall, the women 


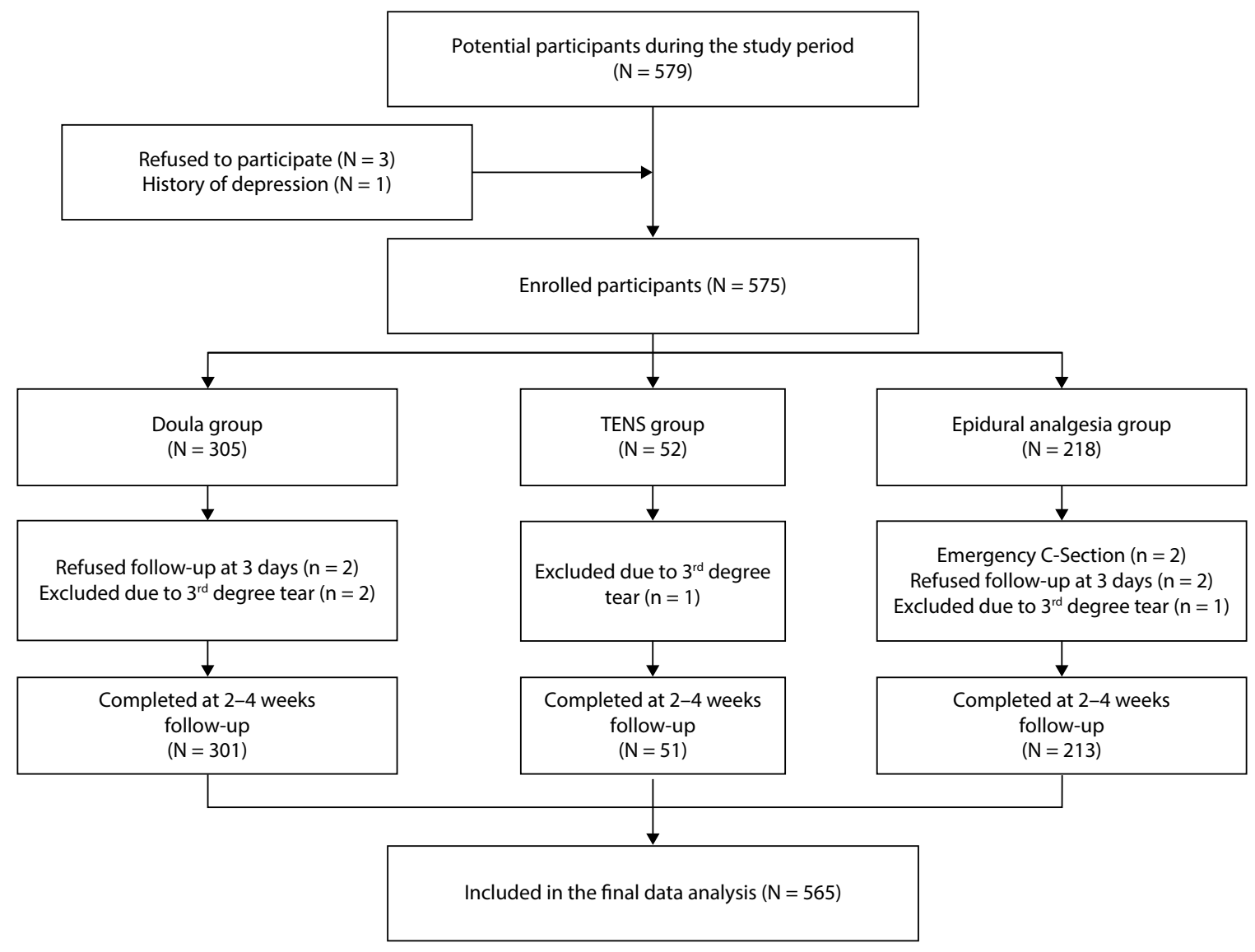

Figure 2. Flow chart showing the enrolment and follow-up status of study

\begin{tabular}{|c|c|c|c|c|}
\hline Variables & Doula $(\mathrm{N}=301)$ & TENS $(\mathrm{N}=51)$ & Epiduralanalgesia $(\mathrm{N}=\mathbf{2 1 3})$ & $P$ value \\
\hline $\begin{array}{l}\text { Age (years, Mean } \pm \text { SD) } \\
(95 \% \mathrm{Cl})\end{array}$ & $\begin{array}{l}28.88 \pm 3.44 \\
(28.49,29.27)\end{array}$ & $\begin{array}{l}28.55 \pm 2.50 \\
(27.85,29.25)\end{array}$ & $\begin{array}{l}28.79 \pm 2.88 \\
(28.40,29.18)\end{array}$ & 0.779 \\
\hline Primipara, n [\%] & $256(85.1)$ & $49(96.1)$ & $196(92)$ & 0.104 \\
\hline Education, n [\%] & & & & 0.447 \\
\hline Primary school & $1(0.3)$ & $0(0)$ & $1(0.5)$ & \\
\hline Secondary school & $35(11.6)$ & $3(5.9)$ & $16(7.5)$ & \\
\hline College & $5(1.7)$ & $2(3.9)$ & $10(4.7)$ & \\
\hline University & $260(86.4)$ & $46(90.2)$ & $186(87.3)$ & \\
\hline $\begin{array}{l}\text { BMI (Mean } \pm \text { SD) } \\
(95 \% \mathrm{Cl})\end{array}$ & $\begin{array}{l}12.77 \pm 4.98 \\
(12.20,13.33)\end{array}$ & $\begin{array}{l}12.84 \pm 1.50 \\
(12.42,13.26)\end{array}$ & $\begin{array}{l}12.90 \pm 1.38 \\
(12.72,13.09)\end{array}$ & 0.919 \\
\hline Employment, n [\%] & & & & $0.017^{*}$ \\
\hline Unemployed & $19(6.3)$ & $3(5.9)$ & $7(3.3)$ & \\
\hline Government / Public Service & $219(72.8)$ & $33(64.7)$ & $161(75.6)$ & \\
\hline Medical personnel & $14(4.7)$ & $2(3.9)$ & $5(2.3)$ & \\
\hline Worker & $26(8.6)$ & $3(5.9)$ & $25(11.7)$ & \\
\hline Farmer & $5(1.7)$ & $0(0)$ & $4(1.9)$ & \\
\hline Teacher & $7(2.3)$ & $3(5.9)$ & $7(3.3)$ & \\
\hline Self-employed & $11(3.7)$ & $7(13.7)$ & $4(1.9)$ & \\
\hline
\end{tabular}

TENS - Transcutaneous Electrical Nerve Stimulation; $* P<0.05$ was considered statistically significant 
had a mean age of 28 years $(P=0.779)$. The majority of the women had a university education. There was a difference in employment between the groups but most women in all groups worked in government/public service; this may be a risk factor for potential depression.

Over $90 \%$ of the women had a spontaneous vaginal delivery, and the duration of the first and second stages of labor was significantly $(\mathrm{P}<0.001)$ longer in the epidural analgesia group compared with the other two groups (Tab. 2).

The mean gestational age of babies in the three groups was almost 39 weeks $(P=0.105)$, with a mean birth weight of $3200 \mathrm{~g}$. The majority of babies had similar Apgar scores at 1 minute and 5 minutes after birth (Tab. 3).

\section{PPD}

At three days postpartum, 546 (96.6\%) women had EPDS scores between 0 and 5 with no significant difference between the intervention groups (Tab. 4).

At two to four weeks, the EPDS scores ranged between $0-5$ for the majority of women in all intervention groups. However, 32 of the 213 (15\%) women had a score between 6 and
9 in the epidural group, which was significantly higher than that for the women in the TENS and doula groups. Two women in the epidural group had a score $\geq 10$, although this was not statistically significant. The EPDS scores were significantly lower among participants in the doula group at two to four weeks after delivery compared with those of women in the TENS and epidural groups (22 of 301 in the doula group vs. 4 of 51 in the TENS group vs. 16 of 213 in the epidural analgesia group, $P=0.006$ ) (Tab. 5). The findings of the current study suggest that while epidural analgesia is an effective method of pain relief during labor, it does not reduce the EPDS score and incidence of potential PPD. Maternal age, being primipara, education, career, $\mathrm{BMI}$, and pain scores were found to be potential confounding variables as they demonstrated some association with PPD. Multivariable logistic regression (Tab. 4) revealed that all variables were not independently associated with PPD in the model.

\section{The Effectiveness of Analgesia during Labor}

Fifty-one participants were administered TENS; 213, epidural labor analgesia; and for 30 , the presence of a doula was

\begin{tabular}{|c|c|c|c|c|}
\hline Variables & $\begin{array}{l}\text { Doula } \\
(\mathrm{N}=301)\end{array}$ & $\begin{array}{l}\text { TENS } \\
(\mathbf{N}=\mathbf{5 1})\end{array}$ & $\begin{array}{l}\text { Epidural analgesia } \\
(\mathrm{N}=213)\end{array}$ & P value \\
\hline \multicolumn{5}{|l|}{ Mode of delivery $n[\%]$} \\
\hline Forceps delivery & $14(4.7)$ & $5(9.8)$ & $13(6.1)$ & 0.252 \\
\hline Spontaneous delivery & $287(95.3)$ & $46(90.2)$ & $200(93.9)$ & \\
\hline \multicolumn{5}{|c|}{ Duration of labor (Mean \pm SD), $(95 \% \mathrm{CI})$} \\
\hline First stage [mins] & $\begin{array}{l}369.47 \pm 183.49 \\
(348.66,390.28)\end{array}$ & $\begin{array}{l}462.80 \pm 188.31 \\
(409.84,515.77)\end{array}$ & $\begin{array}{l}558.07 \pm 216.48 \\
(528.76,587.38)\end{array}$ & $<0.0001^{*}$ \\
\hline Second stage [mins] & $\begin{array}{l}45.81 \pm 33.34 \\
(42.03,49.60)\end{array}$ & $\begin{array}{l}60.06 \pm 36.07 \\
(49.91,70.20)\end{array}$ & $\begin{array}{l}60.08 \pm 37.29 \\
(55.03,65.13)\end{array}$ & $<0.0001^{*}$ \\
\hline Third stage [mins] & $\begin{array}{l}8.00 \pm 4.70 \\
(7.47,8.53)\end{array}$ & $\begin{array}{l}8.84 \pm 6.32 \\
(7.07,10.62)\end{array}$ & $\begin{array}{l}8.47 \pm 6.02 \\
(7.66,9.29)\end{array}$ & 0.444 \\
\hline
\end{tabular}

TENS - Transcutaneous Electrical Nerve Stimulation; *P $<0.05$ was considered statistically significant

\begin{tabular}{|c|c|c|c|c|}
\hline Variables & $\begin{array}{l}\text { Doula } \\
(\mathrm{N}=301)\end{array}$ & $\begin{array}{l}\text { TENS } \\
(\mathrm{N}=51)\end{array}$ & $\begin{array}{l}\text { Epidural analgesia } \\
(\mathrm{N}=213)\end{array}$ & $P$ value \\
\hline $\begin{array}{l}\text { Gestational age [weeks], } \\
(95 \% \mathrm{Cl})\end{array}$ & $39.05 \pm 1.03(38.93,39.16)$ & $39.14 \pm 1.04(38.84,39.43)$ & $39.24 \pm 0.98(39.1,39.37)$ & 0.105 \\
\hline \multicolumn{5}{|l|}{ Neonatal gender $\mathrm{n}$ [\%] } \\
\hline Male & $152(50.5)$ & $26(51)$ & $106(49.8)$ & 0.981 \\
\hline \multicolumn{5}{|c|}{ Apgar score after birth, $(95 \% \mathrm{Cl})$} \\
\hline Apgar score (1 min) & $9.90 \pm 0.55(9.84,9.96)$ & $9.92 \pm 0.34(9.83,10.02)$ & $9.90 \pm 0.88(9.78,9.93)$ & 0.978 \\
\hline Apgar score (5 min) & $9.96 \pm 0.35(9.96,10.00)$ & $9.98 \pm 0.14(9.94,10.02)$ & $9.97 \pm 0.23(9.94,10.00)$ & 0.892 \\
\hline $\begin{array}{l}\text { Infant birth weight }[\mathrm{g}] \text {, } \\
(95 \% \mathrm{Cl})\end{array}$ & $\begin{array}{l}3245.42 \pm 346.14 \\
(3206.15,3284.68)\end{array}$ & $\begin{array}{l}3311.76 \pm 383.09 \\
(3204.02,34419.51)\end{array}$ & $\begin{array}{l}3358.22 \pm 343.52 \\
(3311.82,3404.48)\end{array}$ & 0.161 \\
\hline
\end{tabular}

TENS - Transcutaneous Electrical Nerve Stimulation; *P $<0.05$ was considered statistically significant 


\begin{tabular}{|c|c|c|c|c|}
\hline Variables & $\begin{array}{l}\text { Doula } \\
(\mathrm{N}=301)\end{array}$ & TENS $(\mathrm{N}=51)$ & $\begin{array}{l}\text { Epidural analgesia ( } N \\
=213 \text { ) }\end{array}$ & P value \\
\hline EPDS score in 3 days $(95 \% \mathrm{Cl})$ & $1.50 \pm 1.44(1.34,1.66)$ & $1.49 \pm 1.57(1.05,1.93)$ & $2.17 \pm 1.63(1.95,2.39)$ & $<0.001^{*}$ \\
\hline \multicolumn{5}{|l|}{3 days postpartum } \\
\hline $0-5, \mathrm{n}[\%]$ & $297(98.7)$ & $50(98)$ & $199(93.4)$ & 0.127 \\
\hline $6-9, \mathrm{n}[\%]$ & $3(1)$ & $1(2)$ & $13(6.1)$ & 0.266 \\
\hline$\geq 10, \mathrm{n}[\%]$ & $1(0.3)$ & $0(0)$ & $1(0.5)$ & 0.184 \\
\hline EPDS score in 2-4 weeks ( $95 \%$ Cl) & $2.45 \pm 1.87(2.24,2.66)$ & $2.78 \pm 1.96(2.23,3.34)$ & $3.34 \pm 2.21(3.04,3.64)$ & $<0.001^{*}$ \\
\hline \multicolumn{5}{|l|}{ 2-4 weeks postpartum } \\
\hline $0-5, \mathrm{n}[\%]$ & $279(92.7)$ & $47(92.2)$ & $179(84)$ & 0.129 \\
\hline $6-9, \mathrm{n}[\%]$ & $21(7)$ & $4(7.8)$ & $32(15)$ & 0.145 \\
\hline$\geq 10, \mathrm{n}[\%]$ & $1(0.3)$ & $0(0)$ & $2(1)$ & 0.225 \\
\hline \multicolumn{5}{|c|}{ Potential occurrence of PPD (EPDS score $\geq 6$ ) } \\
\hline 3 days postpartum, $\mathrm{n}[\%]$ & $4(1.3)$ & $1(2)$ & $14(6.6)$ & $0.004^{*}$ \\
\hline 2-4 weeks postpartum, n [\%] & $22(7.3)$ & $4(7.8)$ & $34(16)$ & $0.006^{*}$ \\
\hline
\end{tabular}

${ }^{*} \mathrm{P}<0.05$ was considered statistically significant

Table 5. Multivariable logistic regression models*

\begin{tabular}{|c|c|c|c|}
\hline Postpartum Depression & Odd Ratio & P Value & $95 \% \mathrm{Cl}$ \\
\hline \multicolumn{4}{|l|}{3 days postpartum } \\
\hline Maternal age & 1.000 & 0.977 & $0.857,1.167$ \\
\hline Primipara & 2.040 & 0.291 & $0.542,7.674$ \\
\hline Education & 0.763 & 0.448 & $0.379,1.535$ \\
\hline Career & 1.061 & 0.762 & $0.724,1.554$ \\
\hline BMI & 1.172 & 0.356 & $0.837,1.641$ \\
\hline Before analgesia & 0.952 & 0.880 & $0.506,1.792$ \\
\hline 30 mins after analgesia & 1.404 & 0.258 & $0.780,2.530$ \\
\hline 60 mins after analgesia & 0.802 & 0.531 & $0.402,1.599$ \\
\hline 120 mins after analgesia & 1.164 & 0.612 & $0.647,2.097$ \\
\hline \multicolumn{4}{|l|}{ 2-4 weeks postpartum } \\
\hline Maternal age & 1.018 & 0.811 & $0.879,1.180$ \\
\hline Primipara & 1.738 & 0.407 & $0.470,6.427$ \\
\hline Education & 0.747 & 0.409 & $0.374,1.491$ \\
\hline Career & 1.054 & 0.775 & $0.733,1.516$ \\
\hline BMI & 1.079 & 0.646 & $0.780,1.491$ \\
\hline Before analgesia & 1.146 & 0.464 & $0.795,1.652$ \\
\hline 30 mins after analgesia & 1.168 & 0.375 & $0.829,1.647$ \\
\hline 60 mins after analgesia & 1.282 & 0.235 & $0.851,1.931$ \\
\hline 120 mins after analgesia & 0.899 & 0.640 & $0.545,1.453$ \\
\hline
\end{tabular}

*BMI — body mass index; $\mathrm{Cl}$ — confidence interval; $\mathrm{OR}$ — odds ratio

provided for. The median VAS pain score at baseline (before labor analgesia) was similar (9.0) among the three groups.

The results indicated that the epidural analgesia group had the greatest decrease in pain scores $(9.36 \pm 0.95$ to
$1.24 \pm 0.78)$ after 30 minutes compared with the TENS group (8.94 \pm 0.79 to $6.61 \pm 1.17$ ). Pains scores in the doula group decreased slightly $(9.02 \pm 0.74$ to $8.83 \pm 0.66)$.

During the progression of labor, epidural analgesia was shown to have the greatest effect, with pain scores decreasing to a mean of 1.57 at 60 mins after analgesia. The effectiveness of TENS in reducing pain was greater than that of a doula as indicated by VAS pain scores decreasing from a mean of 8.94 before analgesia to 6.06 at 60 mins and 5.57 at 120 mins after analgesia. In the doula group, the mean pain scores did not decrease much (Tab. 6).

\section{Reasons for Selection of Pain Relief Method}

The participants were asked to provide a reason for their choice of analgesia at the time of their decision. The main reason that the women chose a doula during labor was because they desired personal support (76.1\%, 229/301). Most women who chose epidural analgesia as a pain relief method gave fear of labor pain as the reason for their choice, and indicated they could not endure the labor pain (76.1\%, 162/213). The women who chose TENS did so mainly because of its non-pharmacological effect on pain relief $(37.3 \%, 19 / 51)$, with $23.5 \%(12 / 51)$ choosing TENS as a result of a recommendation from others.

\section{DISCUSSION}

Recent evidence suggests that adequate relief of labor pain may be associated with a decreased risk of PPD [10, $11,13]$. However, there has been no detailed investigation of how different types of labor pain relief (e.g., epidural analgesia, TENS, and doula) may influence the prevalence 


\begin{tabular}{|c|c|c|c|c|}
\hline VAS pain score & $\begin{array}{l}\text { Doula } \\
\text { (N=301) }\end{array}$ & $\begin{array}{l}\text { TENS } \\
(\mathrm{N}=51)\end{array}$ & $\begin{array}{l}\text { Epidural analgesia } \\
(\mathrm{N}=\mathbf{2 1 3})\end{array}$ & $P$ value \\
\hline Before analgesia $(95 \% \mathrm{Cl})$ & $9.02 \pm 0.74(8.94,9.10)$ & $8.94 \pm 0.79(8.72,9.16)$ & $9.36 \pm 0.95(9.22,9.42)$ & 0.436 \\
\hline 30 mins after analgesia $(95 \% \mathrm{Cl})$ & $8.83 \pm 0.66(8.75,8.90)$ & $6.61 \pm 1.17(6.28,6.94)$ & $1.24 \pm 0.78(1.14,1.35)$ & $<0.001^{*}$ \\
\hline 60 mins after analgesia $(95 \% \mathrm{Cl})$ & $8.76 \pm 0.80(8.67,8.85)$ & $6.06 \pm 0.86(5.82,6.30)$ & $1.57 \pm 0.92(1.44,1.69)$ & $<0.001^{*}$ \\
\hline 120 mins after analgesia (95\% Cl) & $8.70 \pm 0.85(8.608 .79)$ & $5.75 \pm 0.82(5.51,5.98)$ & $3.92 \pm 0.97(3.79,4.06)$ & $<0.001^{*}$ \\
\hline
\end{tabular}

${ }^{*} \mathrm{P}<0.05$ was considered statistically significant

of early potential PPD. This quasi-experimental study was designed to investigate the effects of pain relief during labor on the occurrence of potential PPD in early postpartum in a population of Chinese mothers. Labor pain may not be the only variable contributing to the incidence of early potential PPD. However, labor pain may be a modifiable risk factor for early potential PPD.

The reported incidence of PPD varies between 6.5\% and $29.5 \%$ in Chinese women [7]. The prevalence of potential PPD in our study is within this range. In our study, $13 / 213(6.1 \%)$ of the participants in the epidural group had a score between 6 to 9 at three days and 32/213 (15\%) had a score between 6 and 9 at two to four weeks postpartum. These findings are in contrast to those of Ding et al., who found that epidural labor analgesia was associated with a decreased risk of PPD [11]. There are a number of possible reasons for this discrepancy with the previous study. Ding et al. measured PPD at three days and six weeks after delivery, while we tested PPD at three days and two to four weeks after delivery. Although there is no universally accepted time point for PPD screening, depressive symptoms usually occur at two to four weeks after delivery according to Pearlstein et al. [27]. We used a VAS to measure pain, whereas Ding et al. used a numeric rating scale (NRS) pain score [11]. There is also a potential for bias in our study because of the quasi-experimental design.

In our study, the type of analgesia administered differed with respect to the effect on the first and second stages and on repeated pain scores without impacting the mode of delivery or the condition of the baby at birth. However, we found that the mean VAS pain score in the epidural analgesia group decreased the most compared with the TENS and doula groups. This finding is consistent with many other studies that have reported the effectiveness of epidural analgesia for labor pain [28]. In China, the epidural rate has increased rapidly from $10 \%$ to $50 \%$ of all deliveries over the past 10 years [29]. The use of epidural labor analgesia is also high in western countries, varying between $30 \%$ and $69 \%$ in Canada and 60\% in the US. However, epidural analgesia is reported to have side effects including chronic back pain, prolonged duration of the second stage of labor, and a high rate of use of forceps or emergency cesarean section [30]. As a non-pharmacological method for relieving pain in labor, TENS has proven to be safe, non-invasive, easily administered, and cost-effective. In addition, the study by Santana et al. [17] showed that TENS could produce a significant decline in labor pain and decrease the need for additional pharmacological analgesia during labor. In our study, TENS was not as effective as epidural analgesia for pain relief, but there was a small reduction in pain scores in the group. The effectiveness of TENS and a doula were similar, consistent with Bedwell et al.'s literature review, which indicated that women receiving TENS were more satisfied but not because of pain relief. Satisfaction and pain relief are not necessarily the same thing, with pain relief in labor being lower compared with epidural analgesia [31]. Our findings indicated that the effect of pain relief during labor was not significantly associated with the potential occurrence of early PPD by using multivariate logistic regression analysis.

Our study screened for PPD twice throughout the study. In our study, the VAS score in the epidural analgesia group decreased substantially following administration, indicating a reduction in pain. However, the mean EPDS score for women in the epidural analgesia group was higher at three days after delivery (ranging from 0 to 10 ) and at two to four weeks after delivery (ranging from 0 to 14) than for the other two groups, indicating that epidural analgesia during labor did not reduce the occurrence of early potential PPD. These results are in accordance with a recent prospective study by Tobin et al. [32], who reported that epidural analgesia was an effective method of pain relief during labor but that it did not reduce the risk of PPD compared with women who did not receive labor analgesia. Nahirney et al. [33] conducted a secondary analysis of prospective cohort data of urban Canadian mothers and found that there was no significant association between epidural analgesia and PPD at six weeks postpartum.

We found that the doula group had the lowest prevalence of potential PPD in early postpartum. It is well recognized that the fear of childbirth and negative birth experiences are linked with depression. We hypothesize that our results may be associated with the reason given by women 
for their choice of pain relief. More women in the epidural analgesia group reported fear of labor pain (76.1\%) and desired relief from labor pain as soon as possible. Anxiety and depression are known to be comorbid conditions [34]. Antepartum anxiety with respect to labor pain, rather than actual labor pain, might lead to a higher incidence of potential PPD in the early postpartum period. Women who chose doula support did so on the basis of wanting support rather than expressing a fear of pain. A recent randomized controlled trial [35] of first-time mothers in the late third trimester of pregnancy has shown that mindfulness meditation lessens depressive symptoms in the early postpartum period, further strengthening our hypothesis that anxiety and fear of labor is related to potential PPD rather than the type of analgesic received.

\section{Strengths and Limitations}

This study has several distinct strengths. First, it used a representative sample for a province-wide population of pregnant women in China. Second, we had a large sample size and undertook repeated assessments of PPD. Third, the instrument used to measure PPD, that is, the EPDS, has been validated in the Chinese population. The limitations of our study include the quasi-experimental design, convenience sample, selection bias, lack of standardization of the latter time point for administration of the EPDS, which ranged anywhere between two and four weeks postpartum, and that the women's EPDS scores were not measured prior to participation in the study, despite women with a history of psychiatric disorder being ineligible for inclusion.

\section{CONCLUSIONS}

Although the findings of this study showed no statistically significant relationship between the type of analgesia and EPDS scores, we found that women who received epidural analgesia had higher EPDS scores in the early postpartum period. A sufficiently powered randomized controlled trial is required to explain our results. The suggestion that the development of PPD may be ameliorated by addressing a modifiable risk factor, such as anxiety and fear of labor pain, is worthy of further exploration. Specific education on overcoming anxiety and fear of childbirth should be provided in childbirth classes. Childbirth education providers should be equipped with adequate knowledge regarding pain relief interventions in order that they can provide evidence-based and appropriate recommendations.

\section{Relevance for Clinical Practice}

Postpartum is a high-risk period for developing depression and anxiety symptoms. Many risk factors influence the occurrence of PPD. However, anxiety and fear of labor pain are two of the significant risk factors for PPD that ex- ist throughout antepartum, intrapartum, and postpartum. Our results indicated that epidural analgesia did not reduce EPDS scores in the early postpartum period; however, the TENS and doula groups had lower EPDS scores, which demonstrates that reducing labor pain does not decrease EPDS scores and the risk of the incidence of PPD. Because of limitations on visiting policy, most hospitals do not allow the husband to accompany during labor. Doulas, as a continuing support during labor, provide companionship for pregnant women instead of the husband, which may help them overcome anxiety and fear of childbirth. Additionally, specific education on anxiety and fear of childbirth should be provided before labor, which might reduce the risk of the occurrence of PPD in the early postpartum period. Moreover, social support should be provided at each stage of the perinatal period, which might increase women's confidence for childbirth.

\section{Acknowledgements}

Thanks for all of the participants in this study.

\section{Financial disclosure}

This study was supported by the National Natural Science Foundation of China (81371244).

\section{Conflict of interests}

The authors report no conflict of interest.

\section{REFERENCES}

1. Brämer GR. International statistical classification of diseases and related health problems. Tenth revision. World Health Stat Q. 1988;41(1): 32-36, indexed in Pubmed: 3376487.

2. O'Hara MW, Schlechte JA, Lewis DA, et al. Prospective study of postpartum blues. Biologic and psychosocial factors. Arch Gen Psychiatry. 1991; 48(9): 801-806, indexed in Pubmed: 1929770.

3. Andrews-Fike C. A Review of Postpartum Depression. Prim Care Companion J Clin Psychiatry. 1999; 1(1): 9-14, indexed in Pubmed: 15014700.

4. Brett KM, Ramirez SL. Women's health care needs and use: data from the National Center for Health Statistics. J Womens Health. 1997; 6(4): 417-419, indexed in Pubmed: 9279829.

5. Klainin P, Arthur DG. Postpartum depression in Asian cultures: a literature review. Int J Nurs Stud. 2009; 46(10): 1355-1373, doi: 10.1016/j. ijnurstu.2009.02.012, indexed in Pubmed: 19327773.

6. Chi X, Zhang P, Wu H, et al. Screening for Postpartum Depression and Associated Factors Among Women in China: A Cross-Sectional Study. Front Psychol. 2016; 7: 1668, doi: 10.3389/fpsyg.2016.01668, indexed in Pubmed: 27847483.

7. Wan EY, Moyer CA, Harlow SD, et al. Postpartum depression and traditional postpartum care in China: role of zuoyuezi. Int J Gynaecol Obstet. 2009; 104(3): 209-213, doi: 10.1016/j.ijgo.2008.10.016, indexed in Pubmed: 19036364.

8. Wisner KL, Perel JM, Peindl KS, et al. Timing of depression recurrence in the first year after birth. J Affect Disord. 2004; 78(3): 249-252, doi: 10.1016/S0165-0327(02)00305-1, indexed in Pubmed: 15013250.

9. O'hara M, Swain A. Rates and risk of postpartum depression-a meta-analysis. International Review of Psychiatry. 2009; 8(1): 37-54, doi: 10.3109/09540269609037816.

10. Hiltunen $\mathrm{P}$, Raudaskoski $\mathrm{T}$, Ebeling $\mathrm{H}$, et al. Does pain relief during delivery decrease the risk of postnatal depression? Acta Obstet Gynecol Scand. 2004; 83(3): 257-261, indexed in Pubmed: 14995921.

11. Ding T, Wang DX, Qu Y, et al. Epidural labor analgesia is associated with a decreased risk of postpartum depression: a prospective cohort study. An- 
esth Analg. 2014; 119(2):383-392, doi: 10.1213/ANE.0000000000000107, indexed in Pubmed: 24797120.

12. Lim G, Farrell LM, Facco FL, et al. Labor Analgesia as a Predictor for Reduced Postpartum Depression Scores: A Retrospective Observational Study. Anesth Analg. 2018; 126(5): 1598-1605, doi: 10.1213/ANE.0000000000002720, indexed in Pubmed: 29239949.

13. Eisenach JC, Pan PH, Smiley R, et al. Severity of acute pain after childbirth, but not type of delivery, predicts persistent pain and postpartum depression. Pain. 2008; 140(1): 87-94, doi: 10.1016/j.pain.2008.07.011, indexed in Pubmed: 18818022.

14. Gaudet C, Wen S, Walker M. Chronic Perinatal Pain as a Risk Factor for Postpartum Depression Symptoms in Canadian Women. Can J Public Health. 2013; 104(5): 375, doi: 10.17269/cjph.104.4029.

15. Junge $C$, von Soest $T$, Weidner $K$, et al. Labor pain in women with and without severe fear of childbirth: A population-based, longitudinal study. Birth. 2018 [Epub ahead of print], doi: 10.1111/birt.12349, indexed in Pubmed: 29630751.

16. Carlsson AM. Assessment of chronic pain. I. Aspects of the reliability and validity of the visual analogue scale. Pain. 1983; 16(1): 87-101, indexed in Pubmed: 6602967.

17. Santana LS, Gallo RB, Ferreira $\mathrm{CH}$, et al. Transcutaneous electrical nerve stimulation (TENS) reduces pain and postpones the need for pharmacological analgesia during labour: a randomised trial. J Physiother. 2016; 62(1): 29-34, doi: 10.1016/j.jphys.2015.11.002, indexed in Pubmed: 26701166.

18. Vance CGT, Dailey DL, Rakel BA, et al. Using TENS for pain control: the state of the evidence. Pain Manag. 2014; 4(3): 197-209, doi: 10.2217/pmt.14.13, indexed in Pubmed: 24953072

19. Borup L, Wurlitzer W, Hedegaard M, et al. Acupuncture as pain relief during delivery: a randomized controlled trial. Birth. 2009; 36(1): 5-12, doi: 10.1111/j.1523-536X.2008.00290.x, indexed in Pubmed: 19278378.

20. Bohren M, Hofmeyr G, Sakala C, et al. Continuous support for women during childbirth. Cochrane Database of Systematic Reviews. 2017, doi: 10.1002/14651858.cd003766.pub6.

21. Segal D. Diagnostic and Statistical Manual of Mental Disorders (DSM-IV-TR). The Corsini Encyclopedia of Psychology. 2010, doi: 10.1002/9780470479216.corpsy0271.

22. Kennedy HP, Beck CT, Driscoll JW. A light in the fog: caring for women with postpartum depression. J Midwifery Womens Health. 2002; 47(5): 318-330, indexed in Pubmed: 12361343.

23. Peindl KS, Wisner KL, Hanusa BH. Identifying depression in the first postpartum year: guidelines for office-based screening and referral. J Affect Disord. 2004; 80(1):37-44, doi: 10.1016/S0165-0327(03)00052-1, indexed in Pubmed: 15094256.

24. Lau Y, Wang Y, Yin L, et al. Validation of the Mainland Chinese version of the Edinburgh Postnatal Depression Scale in Chengdu mothers. Int
J Nurs Stud. 2010; 47(9): 1139-1151, doi: 10.1016/j.jjnurstu.2010.02.005, indexed in Pubmed: 20219196.

25. Lee DT, Yip SK, Chiu HF, et al. Detecting postnatal depression in Chinese women. Validation of the Chinese version of the Edinburgh Postnatal Depression Scale. Br J Psychiatry. 1998; 172: 433-437, indexed in Pubmed: 9747407.

26. Hawker GA, Mian S, Kendzerska T, et al. Measures of adult pain: Visual Analog Scale for Pain (VAS Pain), Numeric Rating Scale for Pain (NRS Pain), McGill Pain Questionnaire (MPQ), Short-Form McGill Pain Questionnaire (SF-MPQ), Chronic Pain Grade Scale (CPGS), Short Form-36 Bodily Pain Scale (SF-36 BPS), and Measure of Intermittent and Constant Osteoarthritis Pain (ICOAP). Arthritis Care Res (Hoboken). 2011; 63 Suppl 11: S240-S252, doi: 10.1002/acr.20543, indexed in Pubmed: 22588748.

27. Pearlstein T, Howard M, Salisbury A, et al. Postpartum depression in women receiving public assistance: pilot study of an interpersonal-therapy-oriented group intervention. Am J Psychiatry. 2001; 158(4): 638-640, doi: 10.1176/appi.ajp.158.4.638, indexed in Pubmed: 11282702.

28. Howell CJ, Kidd C, Roberts W, et al. A randomised controlled trial of epidural compared with non-epidural analgesia in labour. BJOG. 2001; 108(1): 27-33, indexed in Pubmed: 11213000.

29. Luo BR, Wang L, Yang YL, et al. Retrospective Analysis on the Influence of Epidural Labor Analgesia in Delivery Manner. Int J Anesthesiol Resuscitation. 2009; 30(6): 484-486.

30. Howell CJ. Epidural versus non-epidural analgesia for pain relief in labour. Cochrane Database Syst Rev. 2000(2): CD000331, doi: 10.1002/14651858. CD000331, indexed in Pubmed: 10796196.

31. Bedwell C, Dowswell T, Neilson JP, et al. The use of transcutaneous electrical nerve stimulation (TENS) for pain relief in labour: a review of the evidence. Midwifery. 2011; 27(5): e141-e148, doi: 10.1016/j. midw.2009.12.004, indexed in Pubmed: 20170995.

32. Tobin CD. Labor Epidural Analgesia and Postpartum Depression. Archives of Depression and Anxiety. 2016: 044-046, doi: 10.17352/24555460.000014.

33. Nahirney M, Metcalfe A, Chaput KH. Administration of epidural labor analgesia is not associated with a decreased risk of postpartum depression in an urban Canadian population of mothers: a secondary analysis of prospective cohort data. Local Reg Anesth. 2017; 10: 99-104, doi: 10.2147/LRA.S141569, indexed in Pubmed: 29184440.

34. Räisänen S, Lehto SM, Nielsen HS, et al. Fear of childbirth predicts postpartum depression: a population-based analysis of 511422 singleton births in Finland. BMJ Open. 2013; 3(11): e004047, doi: 10.1136/bmjopen-2013-004047, indexed in Pubmed: 24293208.

35. Duncan LG, Cohn MA, Chao MT, et al. Benefits of preparing for childbirth with mindfulness training: a randomized controlled trial with active comparison. BMC Pregnancy Childbirth. 2017; 17(1): 140, doi: 10.1186/s12884-017-1319-3, indexed in Pubmed: 28499376. 